\title{
Space Wars: The Politics of Games Production in Europe*
}

\author{
Aphra Kerr \\ [pre-print. Forthcoming in Aslinger, Ben and Huntemann, Nina (eds) Gaming Globally. \\ Routledge]
}

Exploring the relationship between the global and the local in media and communications studies has been a focus for international communication scholars for decades. Scholars have focused on where production takes place, on the ownership and control of corporations, on flows between nations, and on the impact of content on audiences and cultures. Theories of dependency and media imperialism gave way in the 1990s to theories of cultural globalization and hybridity. Empirical studies of production and consumption have developed new insights into what happens on the ground and contemporary scholars have become more interested in concepts that attempt to overcome the dichotomy of the global/local and instead focus on the transnational and the translocal. In related fields, like economic geography, the focus has been on regional and local innovation economies. The relationship between place and cultural production has become more complex with globalization and some scholars have become more attuned to the social and political construction of place as a result.

As in other media sectors, it is clear that the global/local opposition may be unhelpful in understanding the production of digital games and how key actors act transnationally. In order to understand how transnational corporations specialize their operations, we need to attend to the ways through which these corporations act in multiple sites. This is not to suggest that the nation-state is no longer important, but rather to state that to understand transnational games production we need to consider how transnational corporations compete, cooperate, and lobby in pursuit of their interests and 
how states and other political entities facilitate, regulate, and collude in these actions. While corporations are headquartered in certain locations, and that remains crucial for them, they may pursue their interests in a range of locations.

Europe is an important market for the global games industry but more importantly for this chapter, it is an important center of game development. However, despite the increasingly global nature of games development, the control of the industry is in the hands of a relatively small number of corporations (Kerr 2011). The games industry, particularly the video games subsector, ${ }^{1}$ is largely controlled by a small number of publishing and techno-publishing corporations headquartered in the United States and Japan. Despite this, transnational game corporations are increasingly establishing branch offices in Canada, Eastern Europe, and China or acquiring successful production studios in dispersed locations. Even in countries with historically strong local-development cultures, like the United Kingdom, the majority of employment in development studios is now in companies owned by transnational corporations (Games Investor Consulting 2008, 9). To a more limited extent, we are also seeing the expansion of Chinese and Indian transnational games corporations into Europe through mergers and acquisitions. We see examples of horizontal and vertical integration, of changing degrees of local/foreign ownership, and of rationalization and movement of workforces. If anything, these forms of economic expansion and concentration have been accelerating in the past decade producing an extensive network of production centers controlled from a limited number of locations. This is clearly economic globalization with companies moving to the cheapest-cost locations (often Eastern Europe), locating near to market, or acquiring new technology and knowledge. Production and services are the most dispersed activities, with publishing somewhat less so and tending to locate in capital cities. These patterns of dispersal mirror to some degree the activities in other cultural industries, particularly film.

However, a second, but less examined trend is also evident and this has much more to do with politics than with economics. In the past decade and a half, we have seen the establishment of industry 
trade associations at national levels to lobby local and regional governments in relation to the introduction of national and local supports for the industry, and at the European level to lobby the European Commission (EC). Entertainment software associations have also been established in the United States and Canada to lobby against content regulation and for state/region and federal financial supports. These formal institutions are a form of alliance where corporations develop their common interests and coordinate their activities locally and transnationally. This chapter is interested in this new form of political transnationalism whereby multinational and local games corporations collaborate to pursue their interests locally, as well as transnationally, via nationaland regionaltrade associations. I consider how the industry is further institutionalizing a boundary between publishers and developers by establishing separate trade associations and how culture is employed strategically in the discourses of these organizations.

In order to examine these developments, this chapter focuses on the parties and discourses involved in the decision by the EC in 2007 to allow France to introduce a tax credit system to aid developers of certain types of video games. This chapter is based on a critical reading of the EC decision, third-party submissions, and press releases released by the various trade associations. It attempts through these documents to identify the actors and to interrogate the discourses they employ. This is not a straightforward state versus industry situation, but rather trade associations for publishers, trade associations for developers, individual corporations, and various public and public/private bodies interacting to shape an emerging discourse around support for European game production and games as a cultural product. In order for countries to justify such state aids under European trade and competition law, they must establish a cultural test and justify it in relation to the European cultural exemption rule. Financial supports for national film industries in Europe, for example, have historically done this.

This chapter attempts to go beyond the structure of the global games industry, which I have examined elsewhere (Kerr 2006), and political economic studies of the industry in particular countries, 
to explore specifically how some actors are acting both transnationally and (trans)locally. To some degree, this chapter puts aside the theoretical argument of whether or not the games industry is a cultural industry (elsewhere, I have argued that it is). It also puts aside the legal technicalities of classifying digital games as a cultural industry, which others can more adequately address (Graber and Burri-Nenova 2010). Instead, it focuses on actors, discourses, and politics in particular national and regional contexts and how these actors attempt to shape how digital games are perceived, measured, and regulated. Beyond acquisitions, subcontracting, and labor movement between firms, the most visible form of institutional extension and networking of corporate power appears to be via national and supranational trade associations.

\section{The Politics of Cultural Production and Policy Making}

As Vincent Mosco $(2009,175)$ points out, the political, in political economy, often gets marginalized or indeed ignored as scholars focus on the activities of particular corporations and countries. This translates into a lack of attention by academics to policy making more generally (Hesmondhalgh 2005, 97). The focus instead has been on media ownership, corporate mergers, revenues, and sales. However, the power of corporations may have been overstated, and the role of other types of national and regional institutions and the politics of their relationships understated. Indeed, Mosco (2009) argues, that while nation-states have a changed role in relation to the media and communication industries, it is not always reactive. Indeed, it may also be constitutive. Certain nation-states and other fora may invite corporations and other actors into the policy process. In the recent World Summit on the Information Society (WSIS) talks, transnational corporations were given sovereign status and sat alongside nationstates and civil society in policy debates (Sarikakis 2008, 101).

Des Freedman (2005) in his research on media policy making in the United Kingdom and the United States points out that lobbying of state policy makers by professional stakeholders has grown exponentially in the past few decades. The growth in numbers of lobbyists, however, does not equate 
with greater transparency or equal access by all. It would appear that certain constituencies are given greater access, particularly if they provide "impartial" statistical or legal arguments to support their case. In a recent report, he concludes that there is "a relationship between industry and government that is marked by its intimacy, lack of transparency and shared objectives" (7). He also argues that it is dominated by a market ideology. Similarly, Sandra Braman (2006) has argued that we are seeing the development of new institutions, treaties, and laws (structural power) at national and international levels, which are introducing and reinforcing certain concepts, practices, and ideologies (symbolic power). For her, we are seeing new forms of information power exercised via both formal and informal mechanisms, and by latent and invisible policy making. Raboy and Padovani (2010) argue that lobbying and advocacy are two of the "less formal, latent, and often invisible processes" through which decision making is informed.

In the past ten years, we have seen calls from a range of actors to increase regulation of game content and access to it. In the past five years, we have seen increasing calls from the games industry for public support in order to protect employment, improve graduate skills, and to protect/maintain game production in Europe. One institutional vehicle for promoting the call for local/national/regional support for the games industry has been industry trade associations. In this chapter, I consider trade associations as one way through which multinational corporations lobby for the further development of locational incentives and as a channel through which transnational and local corporations communicate their goals and interests to national governments. The goal for these actors is the reduction of costs and to deflect, or reduce, the threat of regulation. A key cost for the games industry is labor and while the industry does not necessarily have to locate in high cost cities, as in many cultural industries, the project-based nature of the industry has meant that they do need access to a highly skilled local labor pool. The increasing cost and risk of high-end projects also means that companies are looking for support to offset the research and development costs of new projects. 
Locational incentives and labor costs are issues that have been examined in detail by scholars looking at the film and television industries. While the time scale and logistics of production are different, it would appear that the issues of labor costs, labor contracts, and locational competition in relation to production and certain near to market services are similar. Miller et al. (2001 and 2005) have developed the concept of a new international division of cultural labor, or NICL, to capture how Hollywood exerts control over the global film and television production industry. They argue that "cultural production has mostly relocated within English-language IMECs (industrialized market economies) as factors of production, including state assistance, lure business" $(2005,122)$. For them, the NICL accounts for the greater differentiation of cultural labor, the globalization of labor processes, the means by which Hollywood coordinates and defends its authority over cultural labor markets and the role national governments play in collusion with them (120). In their examination of runaway productions and coproduction agreements, particularly in the 1980s and 1990s, they argue that governments may be "enabling external domination" by "commodifying locations as industry settings of sites and services" (138). Further, they state that certain governments facilitate transnational mobility by increasing local labor market flexibility and by reinscribing and destabilizing national cultural criteria $(177) .^{2}$

Mark Banks in The Politics of Cultural Work (2007) argues that critical scholars like Miller et al. focus too much on large corporations and the macro level without sufficiently interrogating the mechanisms through which cultural production becomes embedded in particular locations. In this chapter, I turn attention to some of these embedding mechanisms at the national and European level. This is not to assert that there is a straightforward influence of the global corporation on the local/national, but rather to trace some of the ways by which global corporations become embedded in different contexts and how they pursue their interests politically. As Marwan Kraidy (Kraidy and Murphy 2008) has pointed out in another context, "a richer notion of the local should enable the exploration of 
power relations within the local and not focus exclusively on power as exercised by the global on the local" (339). Thus, in order to understand the politics of game production in Europe and particularly the activities of transnational corporations, we need to go beyond national borders to understand how the local is constituted and reconstructed in practice.

\section{The Institutional Politics of Game Production in Europe}

L. Hjorth (2008) points out that "in a period marked by transnational flows of people, ideas, and capital, the politics of regionality is indeed a vexed issue" (4). While she was writing about game production in Asia-Pacific, any analysis of games production in Europe needs to attend to the varying national and local cultures of production as well as the larger European legal, economic, political, and cultural context. According to Johns (2006), we can identify three supraregional game production contexts: North American, Europe, and Japan, which are demarcated by technological, economic, social, and cultural barriers. However, these practices and technologies underplay the complexities within these regions and the fact that the European Union (EU) is comprised of 27 member states stretching from the Atlantic Ocean to the Black Sea north of Turkey. While labor may move freely within the EU and associated states, and the Euro currency circulates within a smaller number of states, there are 26 official languages and 60 indigenous languages. The EU is also a unique political institution with a democratically elected Parliament and a Council of 27 commissioners at the core. While strategic economic and trade issues are framed largely at an EU level, cultural, educational, and media policies are still largely a matter for national governments.

The United Kingdom and France have two different systems of government and two different approaches to policy for their cultural industries. The Department of Culture, Media, and Sport (DCMS) in the United Kingdom is responsible for the "creative industries" and a discourse of innovation, research and development, intellectual property (IP) rights, and skills dominates in relation to new media. This is not a discourse of subsidies and grants or culture but rather one of innovation and 
enterprise. The UK government rejected calls for a specific tax credit system for the video games industry in the United Kingdom in 2011 but in 2012 the government launched a public consultation on the issue. To date the focus of policy has been on improving the business climate for companies through research and development tax credits and general business supports.In 2011, the DCMS has its budget cut. .

By contrast in France, games have long been accepted as part of culture and have received grant support for the development of new production projects. The Ministry for Culture in France has not had a budget cut and public financial supports for the French games industry under the Fonds d'Aide au Jeu Vidéo (FAJV) are operated by the Centre National du Cinéma et de L'image Animée (CNC) and the Ministère de L'économie, de L'industrie et de L'emploi. This fund provides subsidies, grants and loans to aid preproduction, new IP generation, industry seminars, and so on (see http://www.cnc.fr/). The French approach to supporting local game production continues a long tradition in that country of public support for cultural production in an attempt to redress the balance of trade with importedcultural products. While the legitimation for such supports may differ from other countries, such supports are not specific to France, with the United States, the United Kingdom, and other countries supporting local cultural production through a variety of financial supports, as Miller et al. (2001) details.

As stated above, globally the control centers of the games industry are in the hands of a small number of multinational publishing and technology companies headquartered in the United States, Japan, South Korea, and China. This is particularly the case in relation to console games. Therefore, Europe is largely a center where development of games and consumption takes place but not necessarily where the value generated by the IP is retained. A recent European report noted that "the UK is the absolute leader (in Europe) with 23 out of the 27 European top ranking (development) studios" (de Prato et al. 2010, 149) although national reports in the United Kingdom point to the fact that over half of employment in the UK industry is in foreign owned companies (Games Investor Consulting 2008). 
In publishing, France leads the way in Europe and Ubisoft is the only European game publisher that ranks in the top-five global publishing studios (de Prato et al. 2010, 52). As a company in the top five, they play a particularly strong and interesting role in terms of the development of French and EU policy for the video games industry. The Nordic countries are also an important center of development, particularly of PC and massively multiplayer online games, and both Iceland and Norway have introduced specific policies to support their games industries.

In both the United Kingdom and France in the past decade, we have seen the development of separate professional game developer and game publisher associations to present their perspectives to local, national, and regional governments. We have also seen the development of panEuropean/transnational associations to lobby European policy makers at an EU level. The Interactive Software Federation of Europe (ISFE) established in 1998, is the European body for game publishers. It is registered in Belgium as an international association with scientific and pedagogical purposes, according to their website. The European Game Developers Federation (EGDF) was established somewhat later in 2006 to represent the interests of development companies and is registered in Sweden. The EGDF is a federation of national trade associations while ISFE has company as well as national trade associations as members. In trying to understand why these associations were established, we can look to a 2002 UK government report which noted that a key issue for the industry was a lack of understanding and appreciation of the size and value of the industry, a perception that jobs in the industry were "not a proper job" and that games were generally perceived as "violent, anti-social" and a "waste of time" (Spectrum. 2002, 23). Another factor may have been the desire of national and European policy makers to deal with unified industry associations rather than multiple interest groups.

These associations support their institutional formation with a range of activities but a particular focus is on the dissemination of information and data about the value of the industry to the national economy and consumer surveys showing the degree to which people play games in each country. On 
the ISFE website, the key issues identified are antipiracy, age rating of games, and education (which refers to games in education and teaching with games). On ISFE's website, they state that they aim to create better awareness of the interactive software industry as a key player in the European economy and as a new vector of European culture; confirm the role of the interactive software industry as a responsible industry by improving various means to inform European consumers on the content of its products and their suitability for different categories of age; establish a source of information for its members and the media on industry data and relevant legislative and technical developments of all kinds through market research on legitimate and pirate sales, press releases and seminars; support national representation in all EU Countries and fight against piracy. (see http://www.isfe-eu.org/)

The United Kingdom's games industry publishing association, UKIE (Association for UK Interactive Entertainment), states that it wishes to "champion the interests, needs and positive image of the videogames and interactive entertainment industry" and to foster "the right economic, political and social environment needed for this expanding industry to thrive." They go on to state that they build "strong working relationships with parliamentarians and policymakers to ensure industry needs are met through appropriate government support" and that they have a "dedicated intellectual property crime unit" which "seeks to minimise the damage caused by intellectual property theft and catch those responsible for this criminal activity." Finally, they work with ISFE "to ensure our members are aware of key EU developments and to promote the priorities and interests of the industry in Europe" (see http://www.ukie.info/about).

Meanwhile The Independant Game developer Association (TIGA), in the UK notes that it "exists to represent and to serve the interests of games developers and associated business." Its vision is to make the United Kingdom the best place in the world to do games business. They focus on three sets of 
activities: "political representation, generating media coverage and developing services that enhance the competitiveness of their members" (see www.tiga.org/What-We-Do.aspx). The European Game Developers Federation (EGDF) states that it is "committed to the stimulation and development of a stable, vibrant and creative European games development sector that is competitive globally and recognized culturally" (see http://www.egdf.eu/). The subtle shift at the European level to include culture is deliberate, as we will see in the deliberations over the French tax credit system. The lack of it at the national UK level appears to reflect the local state discourse of innovation and enterprise. In their bylaws, the EGDF also states that it has a special focus on the interests of "independent developer studios" (see http://www.egdf.eu/EGDF_Bylaws.pdf).

While both UKIE and TIGA want to promote a positive image of the games industry, where they diverge is in relation to the types of member services they offer. TIGA focuses on discounts to attend international conferences, running seminars, negotiating deals on services, and labor supports. UKIE focuses on IP theft and catching those responsible. A second divergence is in terms of their membership: the EGDF explicitly states that it promotes the interests of independent developer studios and is a federation of national state associations. ISFE promotes the interests of the interactive software sector. Its membership includes "thirteen major publishers of interactive software and thirteen interactive software trade associations throughout Europe" (see http://www.isfe-eu.org/). A third divergence is in relation to their use or not of the term culture to refer to the products and services the industry develops. UKIE is not in favor of any supports that conceptualise games as cultural products. ${ }^{3}$

Mosco (1996) points out that political economists have often examined the boards of directors of transnational corporations to establish the relationships between different companies and the degree of concentrated power among board members. An examination of the board of directors of the national and European games publishing associations finds a remarkable degree of overlap. Five companies are on both the boards of UKIE and SELL, ${ }^{4}$ the respective trade associations for game publishers in the 
United Kingdom and France, and ISFE, the European Publishers Association: Activision Blizzard (US), Disney Games (US), Electronic Arts (US), Nintendo Europe (Japan), and Sony Computer Entertainment Europe (Japan). A further three are active in the British and French national trade associationsCodemasters (India/UK), Sega (Japan), and Ubisoft (France)—while one individual, lan Livingstone, life president of Eidos, which is now owned by Square Enix (Japan), is active on the board of both UKIE and ISFE and was one of the authors of a recently released British report on skills for the video games industry in the United Kingdom commissioned by the National Endowment for Science, Technology, and the Arts (NESTA 2011). Ubisoft is the only European top-five publisher active on UKIE, SELL, and ISFE, while the only other European publisher on the board of UKIE is a representative of Mastertronic who serves as chair. In fact, the chair of UKIE represents the only British corporation on the board of UKIE.

What is striking about the national and European publishing associations is the dominance of a small number of large transnational corporations mostly from the United States and Japan. There appears to be a lack of local companies from the countries concerned, a lack of companies operating solely in the mobile, online, and massively multiplayer online games (MMOG) space, and a lack of nonmarket companies involved in serious and educational games. This may help to explain first, the degree to which the policy agendas of both national and European transnational-based game associations coalesce around certain issues, and second, how these agendas are dominated by labor flexibility and cost issues. While the overall agenda in terms of reducing costs of production is shared with the developers' association, the arguments and tools are different. For developers, the argument in favor of state support is justified in terms of conceptualizing games as audiovisual/cultural goods and services and therefore in terms of the social and political necessity to support local cultural production. This argument supports the view that narrative, language, and story are important features of games. It seeks to situate games in policy terms alongside film, television, and other media sectors. For the publishers, games should be as conceptualized as software or interactive entertainment. Their argument 
focuses on the interactive features of games and attempts to situate games in policy terms alongside other software products. The key goal here is to avoid any classifications that might make games subject to content, quality, and distribution regulations in place in Europe in relation to audiovisual and cultural products. The distinctions being made by these associations are reminiscent of the early debates in game studies between narratologists and ludologists, but they have very real economic implications for the parties involved. Since Ubisoft is both a publisher and developer, in the following context, we will see that they broke rank with their fellow publishers and acted to support the development of a French policy to support games production that views games as a cultural product.

\section{The French Tax Credit Scheme for the Creation of Video Games}

In 2005, the French government notified the Directorate General (DG) for Competition of the European Commission that they planned to introduce a scheme whereby certain types of video games could qualify for a tax credit in France. The scheme constituted state aid under EU treaties and therefore France needed to inform the EC of the details of the scheme and the EC needed to decide if it could be allowed under European law. Article 87(1) of the EC Treaty, and in particular derogation 87(3)(d), allows for certain state aids to be developed if they aim to promote culture. The EC accepted in a statement in early 2006 that certain video games "might constitute culture" within the meaning of this article and what was at stake was the selection criteria used by the scheme and the type of content (EC C297/20 7/12/06). They, therefore, called on interested parties to submit comments within one month (EC 2006). Industry associations at all levels in Europe made submissions and while all were in favor of "aid in support of creation of videogames," where they differed was in terms of the "legal, economic and factual bases" (ISFE 2007) for this aid. In these submissions, we see the contrast not only between publisher and developer associations but also between the French and British state approaches to the industry. 
It is important to state that the initiative for this scheme lay with what is described in the official documents as the "French authorities." The process took two years and involved a number of submissions by interested parties and a meeting between representatives of three transnational bodies in Europe-the EC, the ISFE, and the EGDF. Four national trade organizations TIGA (UK), Bundersverband Der Computerspielindustrie (G.A.M.E -Germany and Austria), Asociación Española de Distribuidores y Editores de Software de Entretenimiento (aDeSE - Spain), and Association des Producteurs d'Oeuvres Multimeda (APOM - France) were involved and one transnational French company, Ubisoft. While the documents are not completely transparent, the final, published decision document details the parties who submitted comments and their various positions. The actors marshaled rhetorical arguments, legal precedents, legal treaties, and statistics, and appealed to the UNESCO Convention on the Protection and Promotion of the Diversity of Cultural Expression in their submissions. Intriguingly, or perhaps somewhat depressingly, no mention was made in the decision to any academic studies on the cultural, media, or interactive aspects of video games.

The following is an excerpt from the decision that summarizes the official positions of the European game development association and similar developer associations in the United Kingdom, Germany, and France and was supported by the French publisher/developer UbiSoft. The complex translocal nature of game production and the importance of the national headquarters as a location of control are evident here given that Ubisoft supports the arguments of the national and European game developers associations, rather than its fellow publishing corporations. This highlights the fact that transnational corporations may act locally in some instances and transfer allegiances between transnational associations.

Ubisoft, TIGA, GAME, APOM and EGDF stress that, in their view, video games are cultural products. They emphasise that games in general are one of the oldest cultural traditions of mankind and underscore its interactions with other fields of culture, namely the cinema, music 
and the plastic arts. They present video games as being audiovisual products that can act on the imagination, way of thinking, language and cultural references of players, notably those in the 15-25 age category. According to them, video games reflect the cultural environment in which they are created via the use of language and humour, music, the environment (in particular, architecture and landscapes), and personalities (clothing, origin) or via the scenario, the themes or stories tackled, or playability. (EC 2008, 19)

There are good reasons for the developer associations and others to stress the cultural role of games since this submission was made to the DG Competition of the EC who deals with trade issues and decides if this support mechanism could be allowed under the EC's free trade competition treaty. One of the few areas where state aidis allowed is in relation to culture when the measure aims "(d) aid to promote culture and heritage conservation [but] does not affect trading conditions and competition in the Community to an extent that is contrary to the common interest" (EC 87[d]). Further, this argument reflects the local position of cultural policy toward video games in France. Meanwhile, ISFE in its submissions is summarized as stating,

Video games could not be regarded as cultural products but only as interactive entertainment products. Whereas a film viewer watches in silence, the main activity of a player is to interact in a personalised manner with the game, the story told by the game not being of any real importance. Unlike films, video games are not designed as a vehicle for ideas or cultural messages. Indeed, their main value resides in playability and in interaction with the player or players. ISFE stresses that video games must be regarded as software and not as audiovisual products. It also challenges the idea that the alleged artistic expenditure may represent more than $50 \%$ of the expenditure on a video game's concept. According to ISFE, it is instead the software expenditure-clearly linked to playability-that exceeds all other expenditure and represents up to $70 \%$ of production costs. ISFE also claims that the tax credit demonstrates a 
misunderstanding on the part of the French authorities of the real nature of video games. (EC 2008, 20)

This position reflects that of publisher associations in the United States and Canada. However, the website of UKIE, a constituent member of ISFE, notes that video games are "a new vector of European culture." While this stops short of arguing that video games are cultural products, it points to the oscillating positions of the actors when it comes to arguing for or against policies and legislation, in relation to video games.

Most of the data referred to in the EC decision was submitted by ISFE and the French authorities or obtained from the OECD and the European Audiovisual Observatory. The decision referred to a number of treaties and previous legal decisions but one of the key documents noted is UNESCO's Convention on the Protection and Promotion of the Diversity of Cultural Expressions, which was incorporated into EC law in May 2006. What is remarkable about the appeal to this document is that UNESCO is truly a transnational-or indeed, one might say global-organization and the development of that particular convention was a multistakeholder initiative, which included civil society (see Raboy 2010). This compares favorably to what Raboy calls the G8 and OECD "clubs," or indeed associations like ISFE and the EGDF. While there is some mention of third parties in the EC decision on the tax credit, it is notable that UNESCO was the only body in this process where civil society actors were involved. There is no mention of engagement with academics. The decision notes (EC 2008, 64) that video games "may constitute cultural products" but that this conclusion "in no way prejudges the classification or description of video games resulting from national or international standards."

The tax credit with amendments was finally passed in 2008 and contained detailed "verifiable national" cultural criteria and a selection test to be used in deciding what game projects could be supported. In accordance with the principle of subsidiarity in EC treaties, these tests and the application 
of the scheme was assigned to the relevant public authority in the member state. A first report on the scheme published in 2009 stated that 45 companies met the criteria of "quality, originality and contribution to cultural diversity" in the first round of projects to receive tax breaks. It was stated that the measure would generate between $€ 30$ and $€ 40$ million for the studios operating in France and 90 percent of the estimated $€ 170$ million spent on the projects was spent within France (SNJV. 2009). The president of Syndicate National De Jeu Video (SNJV -formerely APOM), was quoted as saying, "I hope that our experience will help fellow representative bodies across Europe convince their governments to not only put in place a similar tax credit, but also encourage all to pursue the lobbying work that we initiated in Brussels ... all videogames, regardless of nature, are a form of cultural expression and European game creation must now urgently be preserved" (Lee 2009). Meanwhile, the publisher associations ISFE and UKIE continue to assert that games should be seen as software and interactive entertainment and not as cultural products.

\section{Conclusions}

What can we learn about the politics of game production from the development of the French tax credit system for video games? First, publishing and developer trade associations in the games industry are opposed in the matter of whether or not video games constitute cultural products. This position has to do with avoiding content and access regulations developed for cultural industries in Europe. However, even publishers will break with this position if they are located in the national territory in which they might benefit. Thus, the discourse of corporations varies according to certain local and national opportunities. Second, the games industry is increasingly mobilizing its resources to lobby at the national and at the European level. We are seeing a political extension of transcorporation and transnational networks of power in the guise of professional associations. This is in response to not only the perceived negative image of games and the threat of regulation, but also because public policy makers appear to want to interact with unified industry associations rather than individual corporations. 
However, we need to ask to what degree these trade associations actually represent the entire industry or only certain interests within the industry. A small number of transnational corporations are central to the publishing associations at national and European level and appear to have privileged access to policy makers. There also appears to be a high degree of overlap in the membership of these associations between regions. Third, the focus for all industry actors is clearly on reducing the costs of production, whether it is in relation to labor costs or in terms of financial supports to encourage production. Arguably, the locational politics of games production is only just beginning but it is clear that lobbying is increasing at local, national, and European levels.

What we see in the French tax credit case is the initiation of policy by a public state authority and its mediation and shaping by the EC with inputs from industry. From a policy perspective, one sees the importance in European deliberations of legal instruments, legal precedent, and statistics and the irrelevance, or at least the absence of, academic work. A discourse of free trade and market imperatives dominate discussions, which is not surprising given that the scheme was submitted to DG Competition. However, a cultural discourse was also appealed to. The EC noted the UNESCO Convention on the Protection and Promotion of Cultural Diversity and the UNESCO position that games constitute a cultural industry and that some games contribute to cultural diversity was accepted. The EC also noted that games can be both a cultural product and a software/entertainment product or service although this is limited to some, rather than all, games. The final issue is that the details of the cultural tests are developed at a national level and this scheme is implemented by the French authorities with periodical reviews at EC level. It remains to be seen which types of projects and companies actually benefit from this scheme.

National funding of game production, albeit only those with a cultural dimension, is a new departure in Europe. At first glance, this appears to be completely at odds with the more recent ruling in spring 2011 by the US Supreme court that reaffirmed free speech protection for video games and 
rejected attempts by policy makers to intervene in the sale of adult video games. If more countries and developer associations adopt the "French" approach, we are likely to see more public intervention in content development in return for funding. What is unclear is the impact this will have on games. Will we see more cultural diversity in games or will these measures lead to narrow culturally nationalist games? Regardless, transnational corporations will likely relocate, or establish branch operations, in those contexts with the most attractive cost/benefit location, akin to runaway productions in the film industry. Both publisher and developer associations are likely to continue to lobby local governments to introduce more financial supports but less regulation. What is clearer at this stage is that in the EC case no academic input was solicited, while in the US Supreme court judgment, the validity of academic findings on the effects of violent video games on minors was questioned. Game studies still have to find their place in the new political configurations.

\section{References}

Banks, Mark. 2007. The Politics of Cultural Work. New York: Palgrave Macmillan.

Braman, Sandra. 2006. Change of State: Information, Policy and Power. Cambridge, MA: MIT.

De Prato, Guiditta, Claudio Feijóo, Daniel Nepelski, Marc Bogdanowicz, and Jean Paul Simon. 2010. Born Digital/Grown Digital. Assessing the Future Competitiveness of the EU Videogame Software Industry. Seville: European Commission, Joint Research Centre, Institute for Prospective Technological Studies.

European Commission. 2006. State Aid-France. State aid No C27/2006 (ex N648/2005)-Tax credit for the creation of video games. Invitation to submit comments pursuant to Article 88(2) of the EC Treaty. Official Journal of the European Union, 7/12/2006, C 297/19.

- - 2008. Commission Decision of December 11, 2007, on State Aid C47/06 (ex N648/05) Tax credit introduced by France for the creation of video games. Official Journal of the European Union, May 6, 2008, L 118/16.

Freedman, Des. 2005. How Level Is the Playing Field? An Analysis of the UK Media Policy-making Process. London: Economic and Social Research Council. 
2006. "Dynamics of Power in Contemporary Media Policy-Making." Media Culture Society 28: 907-23.

Games Investor Consulting, Ltd. 2008. Raise the Game: The Competitiveness of the UK's Games Development Sector and the Impact of Governmental Support Overseas. London: NESTA.

Graber, Christoph B., and Mira Burri-Nenova. 2010. Governance of Digital Game Environments and Cultural Diversity. Transdisciplinary Enquiries. Cheltenham, UK: Edward Elgar.

Hesmondhalgh, David. 2005. The Cultural Industries. Second edition. London: Sage.

Hjorth, L. 2008. “Games@Neo-Regionalism: Locating Gaming in the Asia-Pacific.” Games and Culture 3: 3-12.

Interactive Software Federation of Europe. 2007. "Comments of ISFE on State Aid Case No C 47/2006Tax Credit for the Creation of Videogames." Accessed on May 23, 2011. http://www.isfe.eu/sites/isfe.eu/files/attachments/letter_to_dg_competition_05.01.2007_2725 508_1_.doc.

Kerr, Aphra. 2006. The Business and Culture of Digital Games: Gamework/Gameplay. London: Sage.

- - - 2011. "The Culture of Gamework." In Managing Media Work, edited by Mark Deuze, 225-36. Thousand Oaks, CA: Sage.

Kraidy, Marwan, and Patrick Murphy. 2008. "Shifting Geertz: Towards a Theory of Translocalism in Global Communication Studies." Communication Theory 18: 335-55.

Lee, James. 2009. "45 Games Approved for French Tax Breaks.” Game Industry.biz, February 23. Accessed May 23, 2011. http://www.gamesindustry.biz/articles/45-games-approved-for-frenchtax-breaks.

Mosco, Vincent. 2009. The Political Economy of Communication: Rethinking and Renewal. London: Sage. Second edition.

Miller, Toby. 2011. "The New International Division of Cultural Labour." In Managing Media Work, edited by Mark Deuze, 87-99. Thousand Oaks, CA: Sage.

Miller, Toby, Niten Govil, John McMurria, and Richard Maxwell. 2001. Global Hollywood. London: British Film Institute. 
Miller, Toby, Niten Govil, John McMurria, Richard Maxwell, and Ting Wang. 2005. Global Hollywood, No. 2. London: British Film Institute.

Mosco, Vincent. 1996. The Political Economy of Communication: Rethinking and Renewal. London: Sage.

NESTA. 2011. Livingstone-Hope Review of Skills for the Video Games and Visual Effects Industries. London: NESTA. Accessed May 23, 2011. http://www.nesta.org.uk/assets/events/livingstonehope_skills_review_of_video_games_and_visual_effects.

Raboy, Marc, and Claudia Padovani. 2010. “Mapping Global Media Policy: Concepts, Frameworks, Methods." Communication, Culture \& Critique 3:150-69.

Sarikakis, Katherine. 2008. "Regulating the Consciousness Industry in the European Union: Legitimacy, Identity and the Changing State." In Global Communications: Toward a Transcultural Political Economy, edited by Paula Chakravartty and Yuezhi Zhao, 95-112. New York: Rowman \& Littlefield Publishers.

Spectrum. 2002. "From exuberant youth to sustainable maturity. Competitiveness analysis of the UK games software sector." London, Department of Trade and Industry (DTI) and Spectrum Strategy Consultants.

SNJV (2009). First assessment on France's 20\% Tax Credit for video games. Assessed $5^{\text {th }}$ Sept, 2012. Avialable online at http://www.snjv.org/data/document/press-release.pdf

\footnotetext{
* This chapter was written while visiting at the Annenberg School for Communication in Philadelphia in 2011. The author would like to thank the faculty and visiting scholars for their support. She would also like to thank Malte Behrmann of the EGDF and David Sweeney of ISFE and Game Ireland for their helpful comments.

${ }^{1}$ I use video games here to refer to the subsector of console games.

${ }^{2}$ A later publication by Miller (2011) notes that the digital games industry "incarnate the centralized labour of production" (94) and that publishers "develop exploitative labour practices" as well as using non disclosure agreements and job threats to discipline workers (95).
} 
${ }^{3}$ Vincent Scheurer has suggested in a speech at the Develop Industry conference in the United Kingdom in July 2011 that UKIE and/or a transnational games publisher may have actively lobbied against the introduction of a games tax relief system in the United Kingdom on the grounds that it might lead to a more "restrictive trade and legal environment” for games. See http://www.sarassin.net/.

${ }^{4}$ Syndicat des Editeurs de Logiciels de Loisirs (SELL) is the French trade association for game publishers. 